\title{
NOVO MÉTODO DE ANÁLISE DA CONTRIBUIÇÃO DAS PROPRIEDADES TÉRMICAS DE MATERIAIS DE CONSTRUÇÃO NO DESEMPENHO TÉRMICO TOTAL
}

\author{
V. F. Mendes ${ }^{1 *}$, W. Fardin ${ }^{1}$, R. R. Barreto ${ }^{1}$, L. M. Martins ${ }^{1}$, L. F. Caetano ${ }^{1}$, J. C. Mendes ${ }^{1}$ \\ *Autor de Contato: vitor.mendes@aluno.ufop.edu.br \\ ${ }^{1}$ Departamento de Engenharia Civil, Escola de Minas, Universidade Federal de Ouro Preto, Ouro Preto, Basil
}

\begin{abstract}
RESUMO
O presente trabalho desenvolveu o Método das Diferenças Acumuladas de Temperatura. Trata-se de uma nova metodologia para a análise comparativa de propriedades térmicas dos materiais de construção, na contribuição para o desempenho térmico total de uma edificação. Esse método foi validado com simulações de uma residência de interesse social hipotética na cidade de São Paulo, na qual foi realizada uma análise de sensibilidade da espessura, massa específica, condutividade térmica e calor específico da argamassa de revestimento. Para isso, foram simuladas 120 argamassas, comparando, de hora em hora, as temperaturas externa e interna. O método foi capaz de apresentar numericamente a influência dessas propriedades no desempenho térmico total, facilitando a comparação e a escolha do melhor cenário construtivo para o resultado final da edificação, em termos de isolamento térmico.
\end{abstract}

Palavras-chave: Desempenho térmico; Eficiência energética; Argamassa de revestimento; Propriedades térmicas; Simulação energética. 


\title{
NEW METHOD OF ANALYSIS OF THE CONTRIBUTION OF THE CONSTRUCTION MATERIALS' THERMAL PROPERTIES IN THE TOTAL THERMAL PERFORMANCE
}

\begin{abstract}
The present work developed the Accumulated Differences of Temperature Method. It is a new methodology to assess comparatively the thermal properties of construction materials, in contribution to the total thermal performance of a building. This method was validated with simulations of a hypothetical low-income residence in São Paulo, in which a sensitivity analysis of the thickness, specific gravity, thermal conductivity, and specific heat of the coat mortar was carried out. For this, 120 mortars were simulated, comparing, every hour, the indoor and the outdoor temperatures. The method was able to present numerically the influence of these properties on the total thermal performance, facilitating the comparison and the choice of the best construction scenario to the final result of the building, in terms of thermal insulation.

Keywords: Thermal performance; Energy efficiency; Coating mortar; Thermal properties; Energy simulation.

\section{NUEVO MÉTODO DE ANÁLISIS DE LA CONTRIBUCIÓN DE LAS PROPIEDADES TÉRMICAS DE LOS MATERIALES DE CONSTRUCCIÓN EN EL RENDIMIENTO TÉRMICO TOTAL}

\begin{abstract}
RESUMEN
El presente trabajo desarrolló el Método de Diferencias Acumuladas de Temperatura. Es una nueva metodología para evaluar comparativamente las propiedades térmicas de los materiales de construcción, en contribución al rendimiento térmico total de un edificio. Este método fue validado con simulaciones de una hipotética residencia de bajos ingresos en São Paulo, en la que se realizó un análisis de sensibilidad del espesor, gravedad específica, conductividad térmica y calor específico del mortero de capa. Para ello, se simularon 120 morteros comparando, cada hora, la temperatura interior y exterior. El método logró presentar numéricamente la influencia de estas propiedades en el rendimiento térmico total, facilitando la comparación y la elección del mejor escenario constructivo para el resultado final del edificio, en términos de aislamiento térmico.

Palabras clave: Rendimiento térmico; Eficiencia energética; Mortero de revestimiento; Propriedades termales; Simulación energética.
\end{abstract}




\section{INTRODUÇÃO}

As condições térmicas do interior das edificações são essenciais para a saúde, bem-estar e produtividade de seus ocupantes. Além disso, as patologias das construções decorrentes de gradientes térmicos (como condensação, trincas, destacamentos, manchas e outros) são de conhecimento geral dos profissionais da área e testemunhados pelos ocupantes que sofrem com o problema, física e psicologicamente. Contudo, os profissionais do setor construtivo carecem de técnicas difundidas e exequíveis que visam apontar soluções viáveis para o projeto de construção, no que se refere ao desempenho térmico. Ademais, não se pode abrir mão da eficiência energética das edificações. Isso, inclusive para aquelas que abrigam famílias de baixa renda em ambientes com grande possibilidade de ser termicamente crítico, devido à escassez financeira com consecutiva falta de profissionais de boa qualificação, materiais de excelência e todas as demais restrições envolvidas que afetam negativamente em uma tomada de decisão assertiva.

À vista disso, a eficiência energética é proporcionada principalmente pelo desempenho térmico da edificação e sucede em uma redução do consumo de energia, em sua grande maioria. Nesse sentido, as propriedades térmicas dos materiais integrantes da envoltória da edificação (os sistemas de vedação externos) têm significativa influência na diferença de temperatura entre o interior e o exterior. Dentre as propriedades térmicas dos materiais de construção, sobressaem-se a capacitância e a transmitância térmicas (Wang et al., 2013).

A capacitância térmica se relaciona com o potencial dos materiais de reter calor. Uma alta capacitância térmica reduz as flutuações de temperatura no ambiente interno, principalmente nas horas de pico (Mengjie et al., 2018). Essa propriedade é diretamente proporcional ao calor específico e massa (ou volume e densidade) do mesmo. Por sua vez, a transmitância térmica se refere à taxa de transferência de calor de um certo material. Quanto menor seu valor, melhor é a sua capacidade de isolamento térmico (Santos et al., 2017). A transmitância térmica é diretamente proporcional à condutividade térmica do material e inversamente proporcional à espessura. Em resumo, quanto maior a espessura do material ou menor a sua condutividade térmica, menor será a transmitância térmica do mesmo, resultando em uma melhor capacidade de isolamento térmico (Pavlík et al., 2014).

Com isso, as propriedades térmicas das argamassas de revestimento, um dos principais componentes das vedações verticais brasileiras, podem influenciar no desempenho térmico das edificações em alvenaria. E essas propriedades variam significativamente. Vários autores conseguiram variar o calor específico das argamassas (Mendes et al., 2020; Onésippe et al., 2010), reduzir a condutividade térmica (Mendes et al., 2020; Onéssipe et al., 2010) e diminuir a massa específica (Benmansour et al., 2014). Parte dessas pesquisas tratam do melhoramento de argamassas compostas por agregados naturais (argamassas convencionais), objeto da aplicação do método apresentado neste trabalho. Além da pesquisa acadêmica, nos últimos dez anos, várias companhias vêm lançando no mercado as "argamassas isolantes", com condutividade térmica reduzida, firmando o compromisso de melhoria na temperatura do ambiente interno (GRXSP, 2021; VIMARK, 2021a; VIMARK, 2021b). No geral, esses e outros estudos avaliam principalmente o impacto de diferentes adições de materiais na propriedade térmica de matrizes cimentícias, mas não analisam se essas alterações contribuem de forma efetiva para a diferença de temperatura entre o ambiente interno e o externo.

Haja vista a necessidade de avaliar o real impacto das argamassas de revestimento no desempenho térmico global das edificações, os autores deste trabalho cogitaram, inicialmente, fazer uso do método de análise recomendado pela norma brasileira NBR 15575 (ABNT, 2013), a qual foca na classificação da edificação em três níveis de desempenho térmico: mínimo, intermediário e superior. Contudo, esse método, na visão dos autores, não se mostra adequado para comparar quantitativamente materiais em relação a sua contribuição no desempenho térmico total da edificação. Além disso, os autores consideraram utilizar a norma estadunidense ASHARAE 90.2 
(2018), a qual trata da eficiência energética do projeto de residências de interesse social. Tal norma aborda o método chamado de graus-dias, que é comumente utilizado em análises térmicas. Todavia, esse método faz uma aproximação questionável pelos autores, ao passo que considera apenas uma média da temperatura externa nas análises, i.e., não considera as variações na temperatura em sua totalidade. Além disso, o método graus-dias apenas se importa com o quanto os resultados extrapolam dos limites regulados pela norma.

Sendo assim, os autores buscaram desenvolver uma metodologia própria para avaliar o impacto da variação das propriedades térmicas dos materiais de construção no desempenho térmico global da edificação. Ou seja, este trabalho visa apresentar um novo método de avaliação quantitativa da influência das propriedades térmicas de materiais de construção no desempenho térmico global das edificações. Para isso, foram analisadas as propriedades térmicas da argamassa de revestimento no desempenho térmico de uma residência situada na cidade de São Paulo (Brasil). São elas: espessura, massa específica, condutividade térmica e calor específico. Através da análise de sensibilidade, a contribuição de cada propriedade é avaliada a partir da diferença de temperatura horária externa e interna. Com este trabalho, almeja-se dar suporte ao processo de tomada de decisão para o isolamento térmico eficiente de uma edificação, considerando os aspectos energéticos e sustentáveis.

\section{PROCEDIMENTO}

\subsection{Método das Diferenças Acumuladas de Temperatura}

Em suma, esse método visa analisar quanto um certo material de construção corrobora como técnica passiva de isolamento no desempenho térmico da edificação. Esse método tem por objetivo medir a diferença entre as temperaturas horárias do exterior (te) e do ambiente interno mais crítico (ti) durante o ano todo (Equação1). Em outras palavras, se plotarmos as temperaturas internas e externas, a distância acumulada entre essas duas linhas formadas é o resultado almejado nesse método de mensurar o desempenho térmico (Figura 1). O somatório foi feito de hora em hora, segundo o padrão do que já é adotado comumente por normas e pesquisas, quando o assunto é análise térmica (ABNT, 2013; ASHRAE, 2018; Benmansour et al., 2014; Wang et al., 2018). Nesse sentido, um resultado negativo de uma dada hora na diferença de temperatura é sinônimo de que o ambiente interno estava mais quente que o ambiente externo. Da mesma forma, um resultado positivo significa que o interior estava mais frio que o exterior. Para isso, os cálculos foram feitos no Microsoft Excel.

$$
\text { Diferença acumulada }=\sum_{\mathrm{k}}^{\mathrm{ano}}\left(\mathrm{te}_{\mathrm{k}}-\mathrm{ti}_{\mathrm{k}}\right)
$$

Nesse sentido, é possível notar semelhanças entre esse método e o chamado graus-dias, que é estipulado pela norma estadunidense ASHARAE 90.2 (2018), dado ao fato de que a criação dos dois métodos parte do mesmo embasamento conceitual. Contudo, o Método das Diferenças Acumuladas de Temperatura considera as especificidades da variação da temperatura externa e interna (valores de hora em hora), além de verificar os valores de forma mais pura, ao invés de prédeterminar limites para verificação de ultrapassagem dos resultados acumulados.

Com esse novo método, o material com as propriedades térmicas que garantem maior resultado em módulo nas diferenças acumuladas (chamado neste trabalho de "acumulado total") garantirá um melhor desempenho térmico para a edificação, já que irá manter o ambiente interno mais bem isolado, com menores oscilações em relação à temperatura externa.

Haja vista que essa metodologia foi criada para tornar notável as diferenças a partir de mudanças nas propriedades dos materiais de construção, o Método das Diferenças Acumuladas de 
Temperatura é recomendado quando os modelos a serem comparados possuem as mesmas condições de contorno, i.e., mesma edificação, arquivo climático e qualquer outra característica existente desconsiderando aquelas do material em questão.

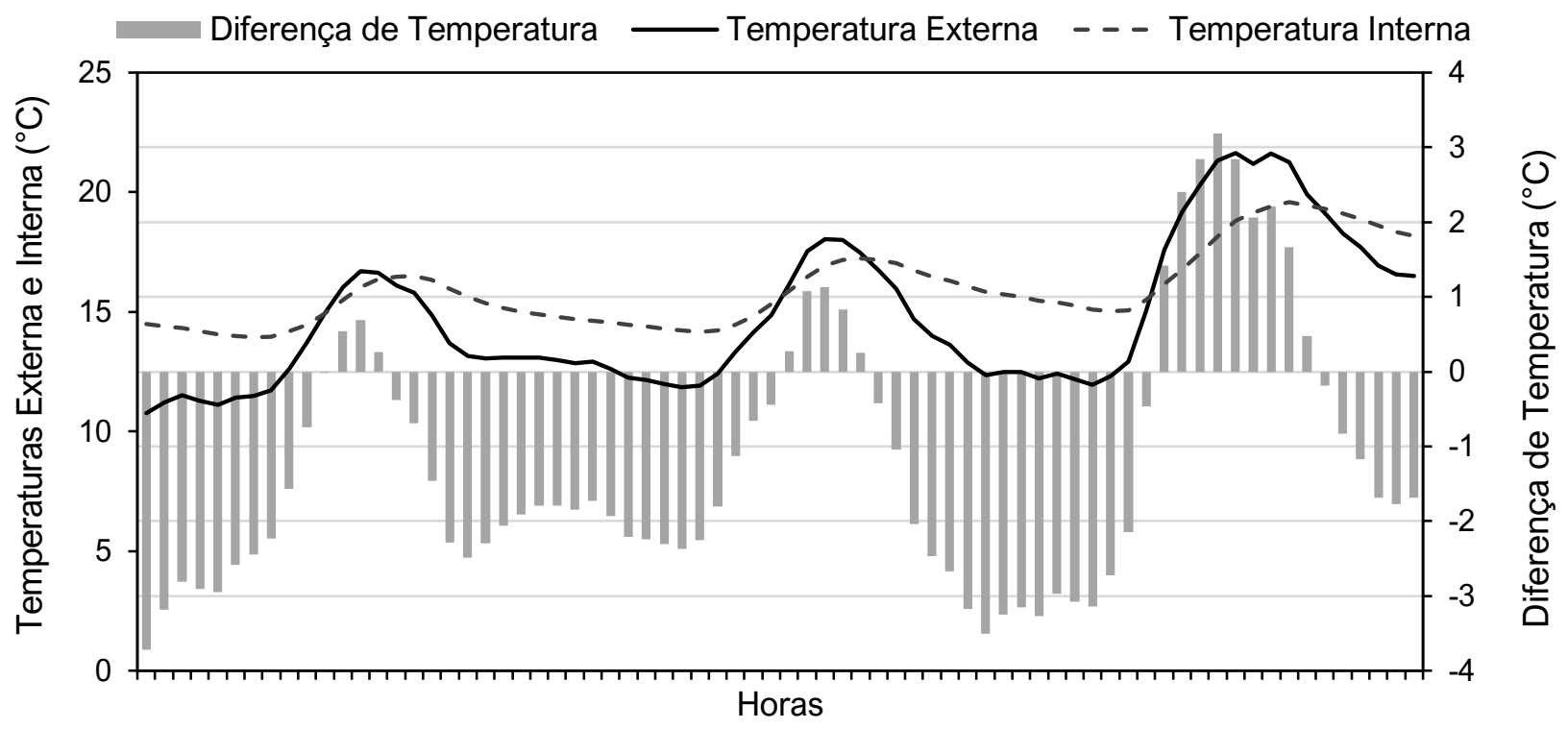

Figura 1. Exemplo de análise do Método das Diferenças Acumuladas de Temperatura, sendo que as colunas cinzas mostram a diferença entre as temperaturas interna e externa.

Outro fator importante é que o Método das Diferenças Acumuladas de Temperatura não é sensível à percepção de conforto humana, focando objetivamente no desempenho térmico da edificação.

Essa situação foi especialmente verificada quando ocorre uma queda brusca na temperatura externa (como a devida a uma chuva no fim de uma tarde quente). Nesses casos, a argamassa com melhores propriedades de isolamento térmico proporcionará uma queda muito vagarosa na temperatura interna, quando comparada a uma argamassa pouco isolante. Ou seja, a argamassa pouco isolante (justamente pela sua baixa capacidade de isolamento) irá resfriar o ambiente mais rápido, o que pode ser favorável aos usuários. De qualquer forma, trata-se de uma pequena limitação do método em relação aos dias que têm quedas bruscas na temperatura.

Os resultados obtidos com esse o Método das Diferenças Acumuladas de Temperatura foram analisados com o auxílio das bibliotecas Matplotlib e Plotly, disponíveis em Python, para a geração de gráfico tridimensional e gráficos de vela.

\subsection{Argamassa de revestimento}

Para a análise de sensibilidade, foram adotadas argamassas de revestimento hipotéticas, cujas propriedades variaram de acordo com o que é apresentado nas normas brasileiras e na ampla literatura. De modo geral, a espessura foi analisada em 5 valores, a condutividade térmica em 4 e o calor específico em 6 valores. Com relação à massa específica, seus valores foram variados segundo a condutividade térmica, como será melhor detalhado a seguir. No total, considerando todas as combinações possíveis, foram simulados 120 tipos de argamassa. A Tabela 1 apresenta os valores que foram considerados para as propriedades térmicas da argamassa. 
Tabela 1. Valores das propriedades térmicas utilizados para as argamassas de revestimento.

\begin{tabular}{|c|c|c|c|}
\hline Propriedade & Unidade & Valor & $\begin{array}{l}\text { Porcentagem } \\
\text { Relativa (\%) }\end{array}$ \\
\hline \multirow{5}{*}{ Espessura } & \multirow{5}{*}{$\mathrm{mm}$} & 10 & 50 \\
\hline & & 15 & 75 \\
\hline & & 20 & 100 \\
\hline & & 25 & 125 \\
\hline & & 30 & 150 \\
\hline \multirow{4}{*}{$\begin{array}{l}\text { Condutividade } \\
\text { Térmica } \\
\text { (Massa Específica } \\
\text { correspondente) }\end{array}$} & \multirow{4}{*}{$\begin{array}{c}\mathrm{kW} /(\mathrm{m} \cdot \mathrm{K}) \\
\left(\mathrm{kg} / \mathrm{m}^{3}\right)\end{array}$} & $1,15(2023,36)$ & 100 \\
\hline & & $0,86(1762,00)$ & 75 \\
\hline & & $0,57(1500,64)$ & 50 \\
\hline & & $0,29(1239,27)$ & 25 \\
\hline \multirow{6}{*}{ Calor Específico } & \multirow{6}{*}{$\mathrm{J} /(\mathrm{kg} \cdot \mathrm{K})$} & 500 & 50 \\
\hline & & 750 & 75 \\
\hline & & 1000 & 100 \\
\hline & & 1250 & 125 \\
\hline & & 1500 & 150 \\
\hline & & 2000 & 200 \\
\hline
\end{tabular}

Como observado na literatura, tratando-se de matrizes cimentícias convencionais, a massa específica da argamassa varia em função da condutividade térmica, devido à propriedade de isolamento térmico dos vazios de ar (Mendes et al., 2019). Em um trabalho anterior, Mendes et al. (2020) comparou a condutividade térmica $(\lambda)$ de mais de 30 argamassas com a massa específica ( $\rho)$ da mesma, encontrando uma relação expressa na Equação $2\left(R^{2}=0,89\right)$. Dessa forma, seguindo as propriedades observadas na prática, os autores adotaram a massa específica aparente da argamassa variando segundo a condutividade térmica.

$$
\lambda(\mathrm{kW} /(\mathrm{m} \cdot \mathrm{K}))=\rho\left(\mathrm{kg} / \mathrm{m}^{3}\right) \times 0.0011-1.0757
$$

Em relação à espessura da argamassa de revestimento, a norma brasileira NBR 13749 (ABNT, 2013) determina que, para paredes internas, ela deve variar entre 15 e $20 \mathrm{~mm}$, e, para as externas, 20 e $30 \mathrm{~mm}$. Contudo, na prática, são facilmente encontradas paredes internas e externas com espessuras de argamassa superior a $20 \mathrm{~mm}$ e inferior a $15 \mathrm{~mm}$. Assim, a espessura foi simulada (igualmente em ambos os lados da parede) adotando $20 \mathrm{~mm}$ um valor padrão (porcentagem relativa considerada como 100\%) e variando-a em 50\%, 75\%, 100\%, 125\% e 150\% (ou seja, entre 10 e 30 $\mathrm{mm})$.

Tratando-se da condutividade térmica e do calor específico, os valores de referência (porcentagem relativa considerada como 100\%) foram concebidos com base na norma brasileira NBR 15220 (ABNT, 2005). Dessa forma, a condutividade térmica foi variada em 25\%, 50\%, 75\% e 100\%, enquanto o calor específico variou em 50\%, 75\%, 100\%, 125\%, 150\% e 200\%. As variações não aumentaram ou diminuíram ainda mais, porque as implementadas já tangem os limites observados na literatura (Mendes et al., 2020; Xu and Chung, 2000; Mendes et al., 2019).

As argamassas foram nomeadas de acordo com suas propriedades, de forma que "e" se refere à espessura, " $\lambda$ " à condutividade térmica e "c" ao calor específico. Por exemplo, "e15- $\lambda 1.15-\mathrm{c} 2000$ " é a argamassa com espessura de $15 \mathrm{~mm}$, condutividade térmica de $1,15 \mathrm{~kW} /(\mathrm{m} \cdot \mathrm{K})$ e calor específico de $2000 \mathrm{~J} /(\mathrm{kg} \cdot \mathrm{K})$. 


\subsection{Edificação simulada}

Neste trabalho, uma residência de interesse social foi simulada no software Energy Plus, versão 8.9. Essa residência é unifamiliar e térrea com 2 quartos e uma área total de $46 \mathrm{~m}^{2}$. Além disso, a casa contém uma cozinha, um banheiro, uma sala e uma lavanderia externa. A Figura 2 apresenta uma visão geral da residência.

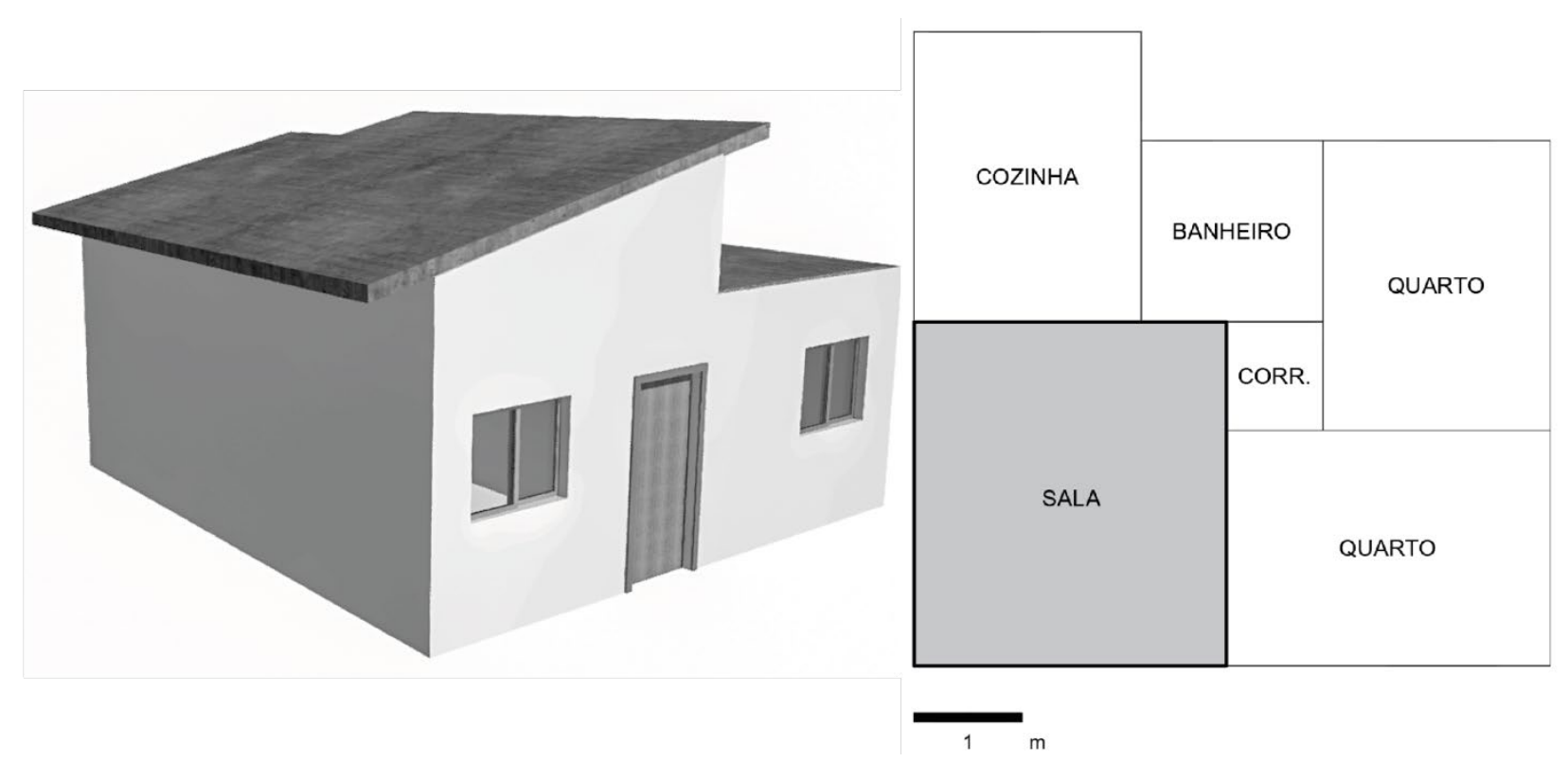

Figura 2. Esquema da residência: direita - modelo 3D; esquerda - planta baixa.

As paredes da residência têm seu núcleo composto por tijolo estrutural de cerâmica de $14 \mathrm{~cm}$ de espessura, revestido com a argamassa de revestimento em questão em ambos os lados. Além disso, todas as paredes têm uma pintura de acabamento com uma tinta que proporciona uma absortância térmica, solar e visível $(\alpha)$ de 0,5 (ABNT, 2005). Quanto ao piso, ele é composto por uma laje de concreto, argamassa comum e piso cerâmico. Como é verificado na maioria das casas brasileiras, não foi considerado nenhum isolamento térmico entre a parte inferior do piso da edificação e o solo. Com relação ao teto, ele compreende uma argamassa comum que reveste a parte inferior da laje e a própria laje de concreto. Com exceção da argamassa de revestimento, as propriedades de todos os demais materiais da edificação (envidraçados, madeiramento e concreto, por exemplo) seguiram os valores da norma brasileira NBR 15220 (ABNT, 2005).

Cada cômodo foi considerado como uma respectiva zona térmica. O cômodo verificado como mais crítico é a sala, logo, ela foi utilizada para as análises de temperatura. Não foi considerada carga térmica interna na edificação (ex. luzes, equipamentos elétricos, pessoas), a fim de isolar o efeito das argamassas no desempenho térmico total da edificação.

Além disso, foi considerada 1 renovação de ar por hora para cada cômodo e a residência foi orientada para o Norte geográfico. Não foi considerado nenhum sombreamento nas envoltórias externas da edificação, a não ser do próprio beiral em certas fachadas da edificação. Também não foi considerada vegetação circundante na casa e a temperatura do solo foi fixada em $18^{\circ} \mathrm{C}$ para todo o ano, seguindo valor padrão do software. Na simulação, considerou-se o arquivo climático, disponível na norma brasileira NBR 15575 (ABNT, 2013), da cidade de São Paulo, localizada na zona bioclimática 3, de acordo com a NBR 15220 (ABNT, 2005). 


\section{RESULTADOS}

A Figura 3 mostra os resultados acumulados das 120 simulações realizadas com a residência de interesse social na cidade de São Paulo. A argamassa e30- $\lambda 1.15$-c2000 totalizou $17186^{\circ} \mathrm{C}$, sendo o maior acumulado total entre todas as argamassas simuladas. Tal destaque viabiliza classifica-la como sendo a melhor opção. Já a e10- $\lambda 0.2875$-c500 tem o destaque de pior, pois garantiu apenas $15235^{\circ} \mathrm{C}$ de acumulado total. Esses valores mostram que, mudando somente a argamassa de revestimento da edificação na faixa de valores abordada neste trabalho, $1951^{\circ} \mathrm{C}$ seriam "salvos" durante todo o ano. Nota-se que essa metodologia é comparativa, ou seja, $1951^{\circ} \mathrm{C}$ é a diferença entre a argamassa de melhor desempenho e a de pior, não existindo um valor mínimo pré-definido. Assim, através deste carácter comparativo, será avaliada a seguir a influência das propriedades térmicas no resultado total do desempenho térmico da edificação.
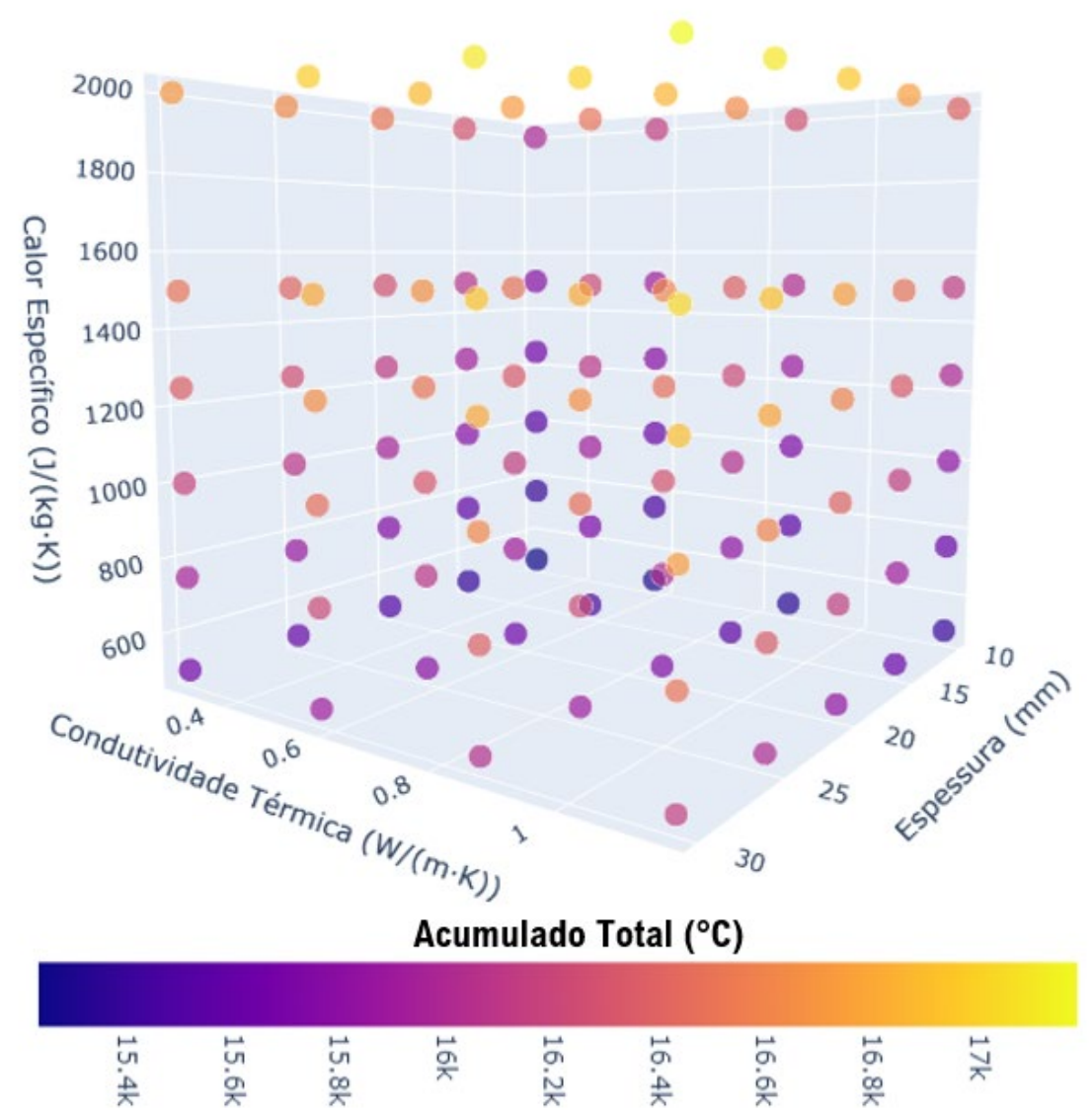

Figura 3. Resultado do acumulado total das 120 argamassas de revestimento simuladas.

A Figura 4 apresenta os resultados de forma bidimensional das 120 argamassas, tendo as propriedades térmicas da argamassa postas lado a lado de acordo com cada resultado de acumulado. De modo geral, verifica-se que as três propriedades térmicas, quando aumentadas, garantem um melhor desempenho térmico total para a edificação. Além disso, verifica-se que a condutividade térmica foi a propriedade que menos influenciou nos três resultados de acumulados, visto que uma dada porcentagem de variação garante menores acumulados (positivo, negativo e total), comparada à mesma variação nas demais propriedades térmicas. Dessa forma, a espessura e o calor específico tiveram maior influência nos resultados. 

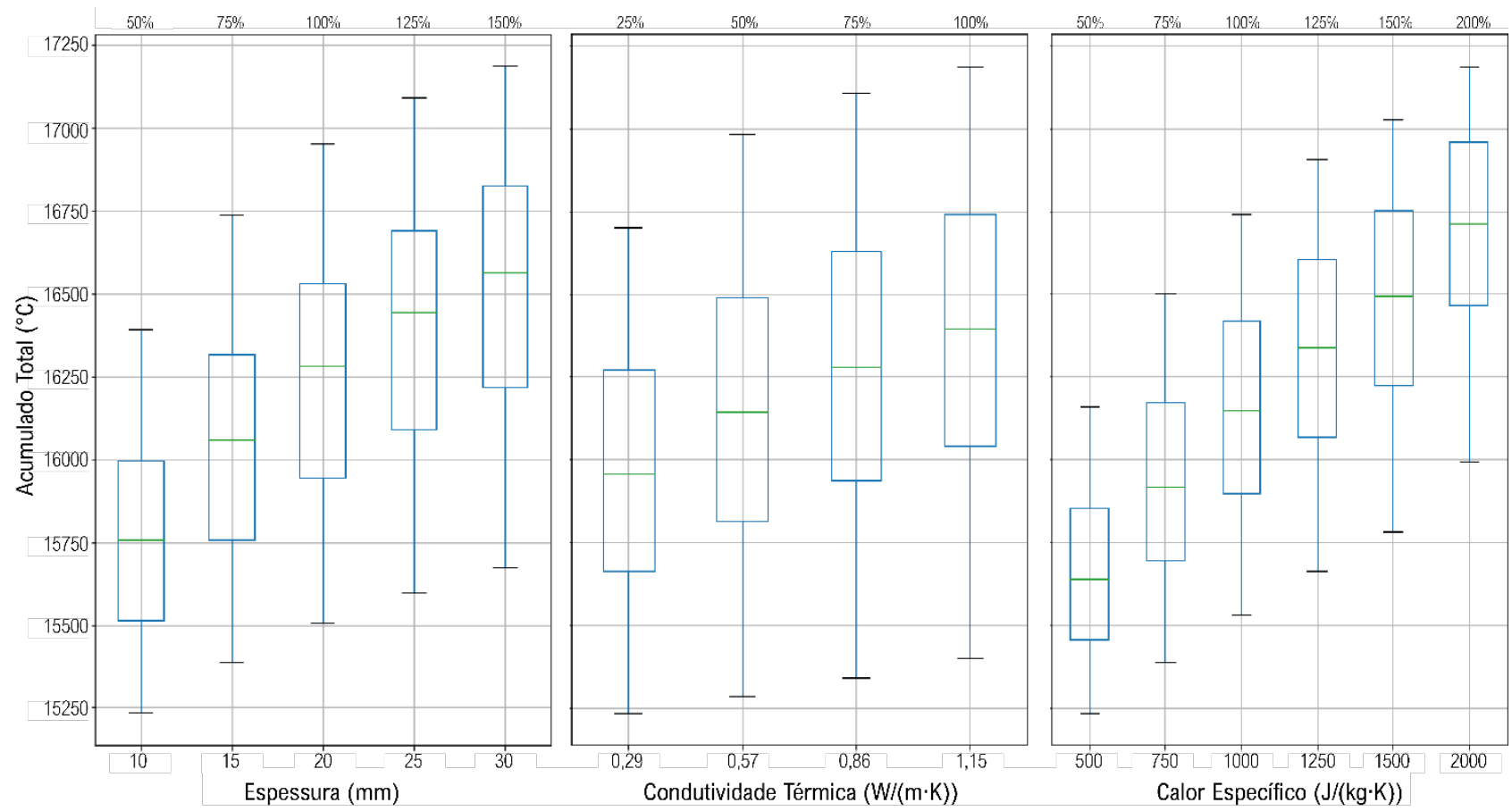

Figura 4. Resultados do acumulado total das argamassas de revestimento separados de acordo com as propriedades térmicas variadas.

Sendo assim, pode-se confirmar que quanto maior a espessura da argamassa e seu calor específico, maior será o desempenho térmico global da edificação. Mas, apesar da espessura e o calor específico cumprirem com o comportamento esperado com relação ao desempenho térmico total da edificação, o mesmo não pode ser dito para a condutividade térmica. É de senso comum que uma baixa condutividade térmica proporciona um aumento da capacidade do material de ser um isolante térmico. Entretanto, para esse modelo, pode-se dizer que o aumento da condutividade térmica aumenta os resultados de diferenças de temperaturas acumuladas. Em outras palavras, o decréscimo na condutividade térmica da argamassa acarretou uma redução na capacidade de isolamento térmico, o que é contrário ao esperado.

Essa disparidade pode ser explicada a partir da variação da massa específica de acordo com a condutividade térmica. Em matrizes cimentícias convencionais, parte significativa da contribuição na redução da condutividade térmica é obtida com a inserção de vazios de ar ou materiais leves na matriz (ex. aditivos incorporadores de ar, agregados de poliestireno expandido, entre outros) (Mendes et al., 2019; Chen et al., 2020; Chen and Liu, 2013). Uma vez que diminuir a condutividade térmica através dessas estratégias causa normalmente uma redução da massa específica, uma redução na transmitância térmica (influenciada pela baixa condutividade térmica) irá resultar em uma queda na capacitância térmica (influenciada pela baixa massa específica).

Dessa forma, as simulações, considerando a análise pelo Método das Diferenças Acumuladas de Temperatura, mostram que a densidade das argamassas é mais influente na capacitância térmica. Um resultado similar foi observado por Franco et al. (2019) e Mendes et al. (2020) quando avaliaram o desempenho térmico de concretos e argamassas com resíduo de mineração e da fabricação de aço.

Assim, esses resultados mostram que as estratégias para diminuir a condutividade térmica da argamassa que também provocam uma baixa na densidade geralmente não são as mais vantajosas para o desempenho térmico total da edificação. 
Dessa forma, é possível notar que o Método das Diferenças Acumuladas de Temperatura consegue avaliar globalmente performances de resultados isolados já consagrados na literatura. Aliado a isso, tem-se a alta credibilidade do software utilizado na análise (EnergyPlus), o qual é o mais confiável e tem sido amplamente utilizado e validado por inúmeros pesquisadores (Crawley et al., 2008). Apesar de validações in loco serem necessárias para a comprovação dos resultados de temperaturas horárias externas e internas, o Método das Diferenças Acumuladas de Temperatura tem por objetivo auxiliar o profissional na escolha dos materiais ainda durante a fase de projeto.

Nesse sentido, essa metodologia traz um melhor auxílio na tomada de decisão, ao conseguir comparar quantitativamente a contribuição passiva das propriedades térmicas de certo material de construção no ganho (ou perda) de desempenho térmico total da edificação de forma direta e sem qualquer influência da subjetividade humana (opinião de conforto, horário de ocupação, vestimenta, aparelhos eletrônicos domésticos, condicionamento do ar etc.). Nesse sentido, esse método também se mostra bastante promissor ao passo que, no geral, guia os resultados para um cenário de bom isolamento térmico, corroborando para a saúde tanto dos usuários quanto da edificação. Questão essa que é muito relevante, haja vista as inúmeras patologias existentes na construção civil que são provenientes dos gradientes de temperatura.

Entretanto, caso esse método seja empregado em todo o território brasileiro, é possível que ele apresente algumas inconformidades nas regiões com predominantes quedas repentinas de temperatura ao longo do dia. No Brasil, a zona bioclimática 8 (ABNT, 2005), por exemplo, é caracterizada por chuvas diárias e frequentes durante todo o ano, as quais causam uma alta e rápida variação térmica no ambiente externo. Tal situação, que foi melhor detalhada no procedimento deste trabalho, faz com que o método possivelmente sugira um material pouco isolante como sendo eficiente para o desempenho térmico da edificação, já que garantirá um maior acumulado total anual, comparado com o material com boas propriedades isolantes. Dessa forma, é notório que esse método se mostra mais efetivo em algumas localidades do que outras. Para regiões em que o método possa provocar resultados dúbios, seria necessário aprimorar essa metodologia que não seja influenciável por essa questão.

Além disso, ao mesmo tempo em que o método faz uma avaliação quantitativa e objetiva da redução da temperatura interna comparada com a externa, o fato de não analisar o conforto térmico dos usuários pode ser uma desvantagem. Ademais, o desempenho térmico é uma necessidade para um conforto térmico dos usuários, que, juntos, corroboram para a eficiência energética das edificações. Ou seja, além de uma análise de desempenho, é importante avaliar se ele supre o conforto dos usuários, a fim de, assim, culminar no ápice da eficiência energética da edificação com a não demanda do consumo de energia para a regulação da temperatura interna (ou, pelo menos, em uma redução nesse consumo).

\section{CONCLUSÕES}

O presente trabalho apresenta e valida o Método das Diferenças Acumuladas de Temperatura, o qual objetiva comparar quantitativamente a influência das propriedades térmicas dos materiais de construção na contribuição do desempenho térmico de uma edificação. Neste caso, foi a analisada as propriedades térmicas da argamassa de revestimento em uma residência de interesse social situada na cidade de São Paulo, referente à zona bioclimática 3 do Brasil (ABNT, 2005). Nesse sentido, 120 argamassas com combinações distintas de valores de espessura, condutividade térmica, massa específica e calor específico foram simuladas e analisadas através do método em questão.

Os resultados mostraram que um aumento nas propriedades térmicas analisadas leva a um melhor desempenho térmico total para a edificação. Em consonância disso, no modelo estudado, com as 
argamassas analisadas, a condutividade térmica, quando aumentada, melhora o desempenho térmico total da edificação, devido ao fato de também acarretar um aumento na massa específica do material, a qual influencia tanto na capacitância térmica (em maior grau) quanto na transmitância térmica (em menor grau). Contudo, a condutividade térmica teve a menor contribuição nos resultados.

Além disso, os resultados desse trabalho demonstraram que a variação nas propriedades térmicas da argamassa de revestimento na residência estudada, na cidade de São Paulo, é capaz de "salvar" até $1951^{\circ} \mathrm{C}$ durante um ano inteiro. Contribuição essa que é bastante significativa no isolamento da temperatura entre o ambiente interno e externo, na qual está diretamente relacionada com o desempenho térmico total da edificação. Cenário esse que é favorável para a minoração das patologias da construção bem como dos problemas físicos e psicológicos dos ocupantes da edificação causados pelos malqueridos gradientes de temperatura, comumente observados nas edificações brasileiras, inclusive nas de interesse social.

Ressalta-se que o método carrega limitações a depender da região analisada e não é valido se o propósito da análise for verificar o conforto térmico dos usuários ou mensurar a economia de energia para manter o interior da edificação em uma faixa de temperatura operativa (i.e., climatização do ambiente). Para essas condições, faz-se necessário a concepção de um método mais abrangente, que seja eficiente para as demais regiões do território nacional (e de todo o mundo).

Sendo assim, esse trabalho auxilia no processo de tomada de decisão para o isolamento térmico de uma residência. O Método das Diferenças Acumuladas de Temperaturas se destaca como uma nova forma de análise e permite elucidar a importância das propriedades térmicas dos materiais de construção, que contribuem passivamente no desempenho térmico total da edificação.

\section{AGRADECIMIENTOS}

O presente trabalho foi financiado em parte pelo Conselho Nacional de Desenvolvimento Científico e Tecnológico $(\mathrm{CNPq})$, através de bolsa de mestrado, e pela Pró-Reitoria de Pesquisa, Pós-graduação e Inovação (PROPPI) da Universidade Federal de Ouro Preto, através de bolsa de Iniciação Científica. Os autores também agradecem ao Programa de Educação Tutorial de Engenharia Civil (PET - Civil) da Universidade Federal de Ouro Preto.

\section{REFERÊNCIAS}

American Society of Heating, Refrigerating and Air-Conditioning Engineers. (2018). ASHRAE 90.2: Energy-Efficient Design of Low-Rise Residential Buildings. Atlanta.

Associação Brasileira de Normas Técnicas. (2005). NBR 15220: Desempenho térmico em edificações. Rio de Janeiro.

Associação Brasileira de Normas Técnicas. (2013). NBR 13749: Revestimento de paredes e tetos de argamassas inorgânicas - Especificação. Rio de Janeiro.

Associação Brasileira de Normas Técnicas. (2013). NBR 15575: Edifícios Residenciais Desempenho. Rio de Janeiro.

Benmansour, N., Agoudjil, B., Gherabli, A., Kareche, A., Boudenne, A. (2014), Thermal and mechanical performance of natural mortar reinforced with date palm fibers for use as insulating materials in building. Energy and Buildings. 81:98-104.

https://doi.org/10.1016/j.enbuild.2014.05.032

Chen, B., Liu, N. (2013), A novel lightweight concrete-fabrication and its thermal and mechanical properties. Construction and Building Materials. 44:691-698.

https://doi.org/10.1016/j.conbuildmat.2013.03 
Chen, Y. X., Wu, F., Yu, Q., Brouwers, H. J. H. (2020), Bio-based ultra-lightweight concrete applying miscanthus fibers: Acoustic absorption and thermal insulation. Cement and Concrete Composites. 103829. https://doi.org/10.1016/j.cemconcomp.2020.103

Crawley, D. B., Hand, J. W., Kummert, M., Griffith, B. T. (2008), Contrasting the capabilities of building energy performance simulation programs. Building and Environment. 43(4):661673. https://doi.org/10.1016/j.buildenv.2006.10.02

Franco, L. C., Mendes, J. C., Costa, L. C. B., Pira, R. R., Peixoto, R. A. F. (2019), Design and thermal evaluation of a social housing model conceived with bioclimatic principles and recycled aggregates. Sustainable Cities and Society. 51:101725. https://doi.org/10.1016/j.scs.2019.101725 GRXSP. Argamassa Termoacústica e Antimanchas Thermo-X (2021). Acesso em: 03/03/2021. https://www.grxsp.com.br/argamassas-e-compostos-especiais/argamassa-termica-thermo-x.html Li, M., Wu, Z., Tan, J. (2013), Heat storage properties of the cement mortar incorporated with composite phase change material. Applied Energy. 103:393-399. https://doi.org/10.1016/j.apenergy.2012.09.05

Mendes, J. C., Barreto R. R., Castro, A. S. S., Brigoloni, G. J., Peixoto, R. A. F. (2020), Factors affecting the specific heat of conventional and residue-based mortars. Construction and Building Materials. 237:117597. https://doi.org/10.1016/j.conbuildmat.2019.117597

Mendes, J. C., Barreto, R. R., Barbieri de Paula, A. C., Pereira da Fonseca Elói, F., Brigolini, G. J., Fiorotti Peixoto, R. A. (2019), On the relationship between morphology and thermal conductivity of cement-based composites. Cement and Concrete Composites. 103365. https://doi.org/10.1016/j.cemconcomp.2019.103

Mendes, J. C., Barreto, R. R., Costa, L. C. B., Brigolini, G. J., \& Peixoto, R. A. F. (2020), Correlation Between Ultrasonic Pulse Velocity and Thermal Conductivity of CementBased Composites. Journal of Nondestructive Evaluation. 39:36. https://doi.org/10.1007/s10921$\underline{020-00680-7}$

Mendes, J. C., Barreto, R. R., Vilaça, V. F., Lopes, A. V., Souza, H. A., Peixoto, R. A. F. (2020), Coating mortars based on mining and industrial residues. Journal of Material Cycles and Waste Management. 22:1569-1586. https://doi.org/10.1007/s10163-020-01051-0

Mendes, J. C., Pinto, P. B., Silva, H. E. A., Barreto, R. R., Moro, T. K., Peixoto, R. A. F., (2019), Macroporous Mortars for Laying and Coating. Journal of Construction. 18(1):29-41. https://doi.org/10.7764/RDLC.18.1.29

Mengji, S., Fuxin, N., Ning M., Yanxin H., Shiming D. (2018), Review on building energy performance improvement using phase change materials. Energy and Buildings. 158:776-793. https://doi.org/10.1016/j.enbuild.2017.10.066

Onésippe, C., Psse-Coutrin N., Toro, F., Delvasto, S., Bilba, K., Asrène, M. -A. (2010), Sugar cane bagasse fibers reinforced cement composites: Thermal considerations. Composites: Part A: applied science and manufacturing. 41(4):549-556. https://doi.org/10.1016/j.compositesa.2010.01

Pavlík, Z., Jerman, M., Trník, A., Kočí, V., Černý, R. (2013), Effective thermal conductivity of hollow bricks with cavities filled by air and expanded polystyrene. Journal of Building Physics. 37(4):436-448. https://doi.org/10.1177/1744259113499214

Santos, G. H., Fogiatto, M. A., Mendes, N. (2017), Numerical analysis of thermal transmittance of hollow concrete blocks. Journal of Building Physics. 41(1):7-24. https://doi.org/10.1177/1744259117698522

VIMARK. Insulating Coat Thermo Rasatura (2021a). Acesso em: 03/03/2021. https://www.grxsp.com.br/argamassas-e-compostos-especiais/argamassa-termica-thermo-x.html VIMARK. Mineral Adhesive-Coating Mortar for Thermal Insulation System Polyfix (2021b). Acesso em: 3 March 2021. https://www.vimark.com/en/prodotti/collante-e-rasante-per-cappottopolyfix/ 
Wang, X., Sun. X., Chuck, Y. W. F. (2018), Building envelope with variable thermal performance: opportunities and challenges. Indoor and Built Environment. 27(6):729-733. https://doi.org/10.1177\%2F1420326X18773928

$\mathrm{Xu}$, Y., Chung, D. D. L. (2000), Effect of sand addition on the specific heat and thermal conductivity of cement. Cement and Concrete Research. 30(1):59-61. https://doi.org/10.1016/s0008-8846(99)00206-9 